\title{
REPUTATION AND HONESTY IN A MARKET FOR INFORMATION*
}

\author{
Gary Charness and Nuno Garoupa \\ Department of Economics and Business \\ Universitat Pompeu Fabra \\ Barcelona, Spain \\ charness@upf.es \\ garoupa@upf.es
}

September 1998

Keywords: Asymmetric Information, Reputation, Insider Regulation, Financial Markets

JEL classifications: C73, C91, D82, G18, K42

\footnotetext{
${ }^{*}$ We thank Antonio Cabrales, James Costain, Rosemarie Nagel, Shyam Sunder, and participants in a pilot experiment for ideas and helpful conversation. The financial support of Spain's Ministry of Education under grant DI01-7715 is gratefully acknowledged.
} 
Abstract: Previous works on asymmetric information in asset markets tend to focus on the potential gains in the asset market itself. We focus on the market for information and conduct an experimental study to explore, in a game of finite but uncertain duration, whether reputation can be an effective constraint on deliberate misinformation. At the beginning of each period, an uninformed potential asset buyer can purchase information, at a fixed price and from a fully-informed source, about the value of the asset in that period. The informational insiders cannot purchase the asset and are given short-term incentives to provide false information when the asset value is low. Our model predicts that, in accordance with the Folk Theorem, Pareto-superior outcomes featuring truthful revelation should be sustainable. However, this depends critically on beliefs about rationality and behavior. We find that, overall, sellers are truthful $89 \%$ of the time. More significantly, the observed frequency of truthfulness is $81 \%$ when the asset value is low. Our result is consistent with both mixedstrategy and trigger strategy interpretations and provides evidence that most subjects correctly anticipate rational behavior. We discuss applications to financial markets, media regulation, and the stability of cartels. 


\section{INTRODUCTION}

Decisions under uncertainty and asymmetry of information are a crucial element in many real world problems and are at the core of research in many fields. Individuals and firms frequently must choose actions with little to guide them. Sometimes relevant information can be acquired at a cost from an informed agent who, unfortunately, may have incentives to distort the truth. Often the underlying asymmetry can be exploited to some financial advantage by the insider, who can choose to sell or otherwise disseminate information to those who could benefit from it.

There may be a temptation to strategically manipulate information to influence markets and thus receive extra rents; however, usually the true state soon becomes common knowledge. The insider must weigh immediate and long-term considerations and the receiver must assess the likelihood that private information is reliable when deciding whether to buy or use it. A major issue is whether a concern for one's reputation and ensuing expected future gains can serve as an effective disincentive against distortion, even when the deception has immediate benefits.

An important regulatory issue is whether the possibility of such manipulation warrants intervention in the public interest. The potential abuse of insider information has been presented as an argument to regulate not only financial and commodity asset markets, but also information markets such as the press. ${ }^{1}$ We examine an information "market" embedded in the context of an asset purchase decision and test whether theoretical cooperative outcomes supported by the Folk Theorem can be obtained in the laboratory. These outcomes require a set of beliefs about players' rationality and behavior, so the result is not obvious ex ante. Our empirical finding is that reputation can be an effective constraint on the distortion of insider information.

\footnotetext{
${ }^{1}$ See Reichman (1993). For example, section 16 of the 1934 Securities Exchange Act forbids "shortswing profits" and the 1990 Securities Enforcement Remedies Act extends criminal liability to insider trading of information An insider is defined to be a person possessing non-public information and short-swing profits are defined as illegal profiting from using non-public information.
} 
Using the Kreps and Wilson (1982) approach, we construct an experimental game where we investigate the extent to which reputation actually deters the manipulation of information. In our framework, the asset value in each period is stochastic and is either high or low, with the parameters set so that the expected gain from making an uninformed asset purchase is zero. An informed agent $(\Gamma)$ can sell information to an uninformed potential asset buyer $(\Phi)$ at an exogenously fixed and strictly positive price, while it is common knowledge that the true asset value will be revealed to all at the end of the period. $\Gamma$ also receives a bonus if the information buyer also buys the asset. ${ }^{2}$ This gives $\Gamma$ an incentive to report a high asset value regardless of the true state.

However, we model the environment as a finitely-repeated game of uncertain duration, where it is common knowledge that $\Phi$ can only obtain advance information from $\Gamma$. This design is intended to simulate a case where $\Gamma$ 's potential profits from manipulating the asset price and trading in the security are negligible compared to the potential profits available from information sales. ${ }^{3}$ The intuition is that a trader (or trader aggregate) $\Phi$ has much greater financial resources than $\Gamma$ has available for her own trading. One could imagine $\Gamma$ to be a financial journalist or guru, while $\Phi$ is some subset of the uninformed public.

There is considerable theoretical and experimental literature on insider trading in asset markets, where decision-makers can extract information from informed players by either purchasing it or observing actions. Central issues are the credibility of the insiders and the mechanism by which information is disseminated in the market. The usual conclusion is that access to private information generates the incentives and the ability to manipulate markets

\footnotetext{
${ }^{2}$ This bonus is not paid by the buyer, but can be viewed as a "kickback" or commission paid by the seller of the security.

${ }^{3}$ This assumption is also made in van Bommel (1998), where $\Gamma$ has a very low "trading capacity."
} 
through strategically-distorted announcements. ${ }^{4}$ However, most studies focus on the marketclearing price of the primary asset market, with all gains and losses occurring in this market. ${ }^{5}$

Some models examine the information market, but still permit the insider to trade in the asset market. Benabou and Laroque (1992) suggest that the insider will make distorted announcements, as the noise in the main market prevents outsiders from being certain whether the insider's message was an blameless error or an attempt to manipulate them. On the other hand, van Bommel (1998) finds that it is optimal for informed traders to disseminate accurate rumors after taking a position. Admati and Pfleiderer (1986) do study a monopolistic market for information where the informed agent can only increase revenues by manipulating the price for information; however, here the price of information is endogenous. They find that the agent charges a price so high that relatively few people buy information.

Experimental markets with asymmetric information usually focus on behavior in the asset market. ${ }^{6}$ Plott and Sunder (1982, 1988), Copeland and Friedman (1987, 1991, 1992), Friedman (1993), and Forsythe, Palfrey and Plott (1984) examine efficiency in relation to some form of rational expectations equilibrium. Sunder (1992) does investigate information markets where information is either sold to each voluntary buyer at a fixed price or auctioned off, but this information must be accurate. We are unaware of any previous experimental research where an insider cannot directly trade an asset, but can sell potentially distorted information about the asset at a fixed price.

Our focus is on the veracity of information sellers when they may have an immediate reason to lie, but are constrained only by reputation. The trade-off is the immediate gain from inducing the purchase of a worthless asset versus potential loss of future revenue when the

\footnotetext{
${ }^{4}$ Credibility and manipulation have been formalized through models of strategic information transmission in which a sender observes the state of nature and then transmits a message to a receiver, who then chooses an action that determines payoffs (Crawford and Sobel, 1982; Sobel, 1985; Benabou and Laroque, 1992).

${ }^{5} \mathrm{We}$ can interpret this story as saying that information conveyed by insiders is a free good and so the market-clearing price in the market for information is zero (either because it is costless to produce it or because there is always excess supply).

${ }^{6}$ Sunder (1995) presents an excellent survey.
} 
manipulation is revealed. The value of a reputation for honesty is the key determinant. Yet, reputation only matters under certain sets of beliefs about rationality. Our experiment tests whether these beliefs are strong enough for a good reputation to have significant value.

The main result of the paper suggests that the insiders' incentive to manipulate information is substantially limited by the expectation of future revenues. We find that even when the true asset value is low, sellers provide accurate information with an $81 \%$ probability, generally resisting the temptation to secure an immediate commission by lying. This ex post observed probability is high enough to make it optimal to purchase information. We also observe considerable efficiency in the asset market, as measured by the overall performance of the assets purchased. We briefly describe several policy implications for financial markets, media behavior, cartel stability, and political economy.

\section{THE MODEL}

An individual trades an asset whose return is contingent upon the state of the nature $\mathrm{S}$ $\in\{-1,1\}$. The asset pays $\mathrm{r}$ if $\mathrm{S}=1$ and zero if $S=-1$. Each of these outcomes has probability one half, and the outcome becomes known to all only at the end of the period. The asset has value in exactly one period and can be bought at the beginning of the period for a price $\mathrm{y}$. Assuming that individuals are risk neutral and absent private information, there is a market for this asset as long as $y<=r / 2$. We set $y=r / 2$.

At the beginning of each period, an insider (a journalist, a consultant or a message sender) privately observes either $S$ or a signal that predicts the state of the nature with probability one. He can offer to sell, at a price $\mathrm{p}$, information about this state to an individual trading in the asset market. Furthermore, if an individual does buy the asset, the insider gets a bonus given by q (imagine that the sender is commissioned by the seller of the asset). This information structure is common knowledge.

The buyer learns $\mathrm{S}$ after the trading period, and consequently knows if there has been manipulation of information. The insider knows that any attempt to manipulate information is 
detected with probability one after the trading period. Figure 1 shows the extensive form for this game. Nature chooses $\mathrm{S}$. Without observing nature's move, the buyer B chooses between buy information (Bi) and not buy information and buy asset (Ni). Given the opportunity, the sender observes $\mathrm{S}$ and decides between announcing $\mathrm{S}=1$ and $\mathrm{S}=-1$. The buyer observes the sender's announcement and decides between buying the asset $(\mathrm{Ba})$ and not buying the asset $(\mathrm{Na})$. 


\subsection{One-shot game}

Suppose the message technology is such that the sender cannot lie. The expected payoff for the buyer is then $\mathrm{r} / 4$ - p, given that he does not buy the asset if the sender announces $\mathrm{S}=-1$. As long as $\mathrm{p}<\mathrm{r} / 4$, the buyer always buys information. The seller gets $\mathrm{p}+\mathrm{q}$ if $S=1$ and $p$ if $S=-1$.

However, matters are very different if we permit the seller to lie. Now the seller has an incentive to state that $\mathrm{S}=1$, independently of the observed $\mathrm{S}$. By doing so, the seller keeps alive the chance to receive $q+p$ rather than just $p$.

Let us solve the game backwards. From Figure 1, if the sender announces $S=-1$ then the buyer does not buy the asset. If the sender announces $S=1$ he believes with probability A that $\mathrm{S}=1$. In this case, he buys the asset if $\mathrm{A}>1 / 2$. When the sender observes $\mathrm{S}=-1$ announcing $S=1$ strictly dominates announcing $S=-1$. Then, at equilibrium, $A=1 / 2$. Paying the insider provides no useful information. The expected payoff from choosing $\mathrm{Bi}$ is $-\mathrm{p}$ and the expected payoff from choosing $\mathrm{Ni}$ is zero. Thus, Ni is preferred to $\mathrm{Bi}$.

The unique perfect Bayesian equilibrium of the game is described by the buyer choosing $\mathrm{Ni}$; the sender announcing $\mathrm{S}=1$ if information is bought and $\mathrm{S}=-1$ is observed; the buyer believing with probability $1 / 2$ that $S=1$ when the seller announces $S=1$ and with probability $1 / 2$ that $S=-1$ when the seller announces $S=1$; and the buyer randomizing between $\mathrm{Ba}$ and $\mathrm{Na}$. The buyer should anticipate that the seller always lies when $\mathrm{S}=-1$ and so knows the sender's message does not convey any information. He decides not to buy information and either buys the asset or not, depending on risk aversion and whether he feels lucky. Both the insider and buyer have expected payoffs of zero and so both are worse-off from the situation where the buyer purchases the information and the sender is honest. The problem here is that the sender cannot credibly commit himself to always tell the truth. 


\subsection{Repeated game}

Consider a repeated game where buyer and seller are to play forever. Can the sender credibly commit himself to consistently tell the truth? The Folk Theorem for infinitely repeated games says that there exists a minimum discount factor above which cooperative strategies can be supported as a Nash equilibrium. ${ }^{7}$ This result can also be invoked for finitely repeated games with an uncertain number of rounds (Benoit and Krishna, 1985, 1987; van Damme, 1991). Suppose the buyer uses a grim trigger strategy: if he discovers he has been manipulated, he never buys information again. Otherwise, he always buys information. When $\mathrm{S}=-1$ is observed, the sender has to decide whether to lie. ${ }^{8}$ By reporting the truth, the seller expects to earn $p+z(p+q / 2)$, where $z$ represents the expected number of subsequent periods ${ }^{9}$ and $\mathrm{p}+\mathrm{q} / 2$ is the future expected earnings per period; if he lies, he gets $\mathrm{p}+\mathrm{q}$. As long as $\mathrm{z}>$ $\mathrm{q} /(\mathrm{p}+\mathrm{q} / 2)$, the sender always tells the truth.

Two cases are straightforward: (1) suppose $\mathrm{p}$ is near zero and $\mathrm{q}$ is large (the insider's gains come from the asset market): the critical value for $\mathrm{z}$ is 2 and for any $\mathrm{z}<2$ the seller lies and there is no market for information; (2) suppose p is large and q is zero (the insider's gains come from the market for information): the seller always tells the truth because he wants to maintain the demand for information. The parameter values used in the experiment are $\mathrm{p}=50$ and $q=40$, so that the critical value of $z$ is given by $4 / 7$; that is, for any $z<4 / 7$ the seller reports the asset value to be high even when it is actually low, so there is no market for information.

\section{2.a. Finite game}

In a finite repeated game, there is an unraveling problem. We know that the unique perfect Bayesian equilibrium of the meta-game is for the seller to lie (if $S=-1$ occurs) and for

\footnotetext{
${ }^{7}$ Of course, even if the sufficient condition is satisfied, the set of possible Nash equilibria is infinite. ${ }^{8} \mathrm{We}$ assume throughout this section that a sender accurately reports a true high asset value with probability 1 . The observed probability was .97 .

${ }^{9}$ In principle $\mathrm{z}$ should also be discounted over time. However, in the experiment $\mathrm{d}=1$.
} 
the buyer not to buy information. Using backwards induction, the seller will always state $\mathrm{S}=1$ in the last period T; since the buyer anticipates this, he will not buy information in this period. In period T-1, the seller knows that he cannot be punished next period because the buyer will not buy information in any case, so he again always states $S=1$ in this period. Once again, this is anticipated by the potential buyer; we can generalize the argument to the first period and so cannot improve on the equilibrium of the stage game.

Suppose instead that there are s periods played for certain, after which there is a probability (hazard rate) $\Pi>0$ that the session ends after each round, so that $\mathrm{p}(\mathrm{T}+1)=1-\Pi \forall$ $\mathrm{T} \geq \mathrm{s}$. Note that at any point after period $\mathrm{s}$, the expected number of further periods is $1 / \Pi$. In this case the part of the session with stochastic duration is expected to be a finite game of $\mathrm{T}=$ $1 / \Pi$ periods, but the game cannot be solved backwards as before because the final period is uncertain.

Define $\mathrm{z}=\mathrm{T}-1$. Suppose the buyer uses a grim trigger strategy, defined as buying information if and only if there have been no observed false asset value reports. From the preceding section and the above definition of $z$, we can say that for any $T>(p+3 q / 2) /(p+q / 2)$, the sender always tells the truth. If the buyer plays the grim trigger strategy and the critical value of $\mathrm{z}$ is $4 / 7$, we argue that if players expect to play for two or more periods, the sender always tells the truth.

We obtain a similar result with a transitory punishment phase. Assume that the buyer punishes the sender for $\mathrm{N}$ periods if deceived. The sender compares the payoff from being honest for $\mathrm{T}$ periods, $\mathrm{p}+(\mathrm{T}-1)(\mathrm{p}+\mathrm{q} / 2)$, with the payoff from lying and being punished for $\mathrm{N}$ periods given that $\mathrm{S}=-1$ has been observed, $\mathrm{p}+\mathrm{q}+(\mathrm{T}-\mathrm{N}-1)(\mathrm{p}+\mathrm{q} / 2)$. As a consequence, as long as $\mathrm{N}>\mathrm{q} /(\mathrm{p}+\mathrm{q} / 2)$, the sender is honest.

\section{2.b. Mixed strategies}

An alternative view of this repeated game is to assume that the seller randomizes between announcing $S=1$ and $S=-1$ when $S=-1$ is observed in the meta-game. Define $j$ as 
the probability that $S=1$ is announced when $S=-1$ is observed. If the receiver purchases information, he receives $\mathrm{r} / 4$ - jr/4 - $\mathrm{p}$ each period. He forms an opinion about $\mathrm{j}$ based on observing either historical behavior or a randomizing device. As long as $\mathrm{j}$ is less than $1-4 \mathrm{p} / \mathrm{r}$ the buyer buys information and then buys the asset if and only if the message states that $\mathrm{S}=1$.

The sender's payoff per period is $\mathrm{p}+\mathrm{q} / 2+\mathrm{jq} / 2$ if $\mathrm{j}$ is less than $1-4 \mathrm{p} / \mathrm{r}$ and zero if $\mathrm{j}$ is greater than $1-4 \mathrm{p} / \mathrm{r}$ (since there is no market for information). If the buyer's strategy is to purchase information with non-negative expected net value, based on his beliefs about the value of $\mathrm{j}$, he will do so if and only if he believes $\mathrm{j} \leq 1-4 \mathrm{p} / \mathrm{r}$. In this case, it is optimal for the sender to randomize with $\mathrm{j}=1-4 \mathrm{p} / \mathrm{r}$. When $\mathrm{p}=50$ and $\mathrm{r}=320$, $\mathrm{j}$ is given by 0.375 . In other words, as long as the sender tells the truth with a probability greater than 0.625 when $S=-1$ is observed (and always tells the truth when $S=1$ ), there is a market for information. Before $S$ is observed, we can say that the truth should be conveyed to the buyer with probability 0.8125 .

We must be careful in defining the randomization mechanism; that is, how the sender sets $\mathrm{j}$. If the buyer is not able to observe and verify the sender's randomization, we can have $\mathrm{j}=1$ $4 \mathrm{p} / \mathrm{r}$ and yet the sender's message will always be "high." To make sure that the buyer's belief $\mathrm{j}$ is supported at the equilibrium we need a verification mechanism.

A possible example of a verification mechanism is for the buyer to argue that for each ten periods, he should observe the seller lying $5 \mathrm{j}$ periods. For the example where $\mathrm{j}=0.375$, we have $5 \mathrm{j}=1.875$. In other words, if the buyer observes the seller lying for two periods in a row of ten periods, the buyer knows his belief that $\mathrm{j}=1-4 \mathrm{p} / \mathrm{r}$ is wrong and he stops buying information. There are two implications from this result. First, we should observe the seller lying at most once in each ten periods; second, information is purchased even after the seller lies for the 1 st time.

There is a small but potentially important caveat to this result. It may be the case that people have an aversion to being manipulated, over and above any pecuniary considerations. This could be a rationale for playing the grim trigger strategy. If such an aversion is present it 
will be prudent for the seller to choose a smaller $\mathrm{j}$, according to the degree of distaste for being manipulated.

\subsection{Optimism and pessimism}

The likelihood of $\mathrm{S}=1$ at period $\mathrm{T}$ is independent from the state of the world at period T-1. Moreover, at each period, a coin is thrown to determine the state of the world and the probability of $S=1$ is $1 / 2$. We distinguish optimism and pessimism as beliefs that the likelihood of $\mathrm{S}=1$ is not 1/2: given the observation of the world at $\mathrm{T}-1$, one may be optimistic or pessimistic about the world at period T. These beliefs are taken as exogenous to the model. Consider the finite repeated version of the game where $\mathrm{T}$ is the expected number of periods.

Start by analyzing the seller's decision. Suppose she thinks that $S=1$ occurs with probability $=\mathrm{k}$. For $\mathrm{k}>1 / 2$, we say that the seller is optimistic and for $\mathrm{k}<1 / 2$ we say that the seller is pessimistic. Applying results derived before, cooperation is achievable if $\mathrm{T}>[\mathrm{p}+(\mathrm{k}+1) \mathrm{q}] /[\mathrm{p}+\mathrm{kq}]$. Observe that the right-hand side of the expression decreases with $\mathrm{k}$ : it is easier to achieve cooperation if the seller is optimistic.

Conversely, consider the case of the buyer. The payoff from buying information is kr/2-p. The payoff from not buying information is $\max \{(\mathrm{k}-1 / 2) \mathrm{r}, 0\}$, where the first term refers to the case where the asset is bought and the second to the situation where the asset is not bought. The buyer buys information if $2 \mathrm{p} / \mathrm{r} \leq \mathrm{k} \leq 1-2 \mathrm{p} / \mathrm{r}$ (for $\mathrm{p} / \mathrm{r}<1 / 4$ ). In the case of our example, $0.3125 \leq \mathrm{k} \leq 0.6875$. Summarizing, we can say that the likelihood of a market for information existing increases with the degree of optimism exhibited by the seller, as long as the buyer is neither too optimistic nor too pessimistic.

\subsection{A Note on Bankruptcy}

In the previous discussion we have implicitly assumed that a buyer cannot become bankrupt. This is equivalent to the case where a buyer has an infinite debt capacity. This convenient assumption is translated into the experiment by giving the buyers a substantial 
initial endowment, so that bankruptcy does not play an important role in the game. However, for the sake of completeness, we further discuss the game when a liquidity constraint is binding.

Consider the extreme case where the buyer becomes bankrupt if he buys the asset when $S=-1$. Here, the seller has less incentive to lie. The possibility of bankruptcy works as a grim trigger strategy mechanism: if the seller lies to the buyer, the buyer will never buy again because he does not have the money to do so. So the possibility of bankruptcy should favor cooperation. In a sense, the possibility of bankruptcy is good for both players because it makes more credible for the buyer to use a grim trigger strategy and for the seller to be honest from day one.

In the context of mixed strategies, the possibility of bankruptcy puts pressure on the seller to opt for a smaller $\mathrm{j}$. Consider the case where buyer and seller expect to play for two periods. When bankruptcy is not binding, the expected payoff if the buyer buys information and the seller announces $S=1$ when $S=-1$ with probability $\mathrm{j}$ is $2[\mathrm{r}(1-\mathrm{j}) / 4-\mathrm{p}]$. When bankruptcy is binding, the expected payoff is $(2-\mathrm{j} / 2)[\mathrm{r}(1-\mathrm{j}) / 4-\mathrm{p}]$, that is, the expected payoff is smaller than when bankruptcy is not binding. As a consequence, we can say that buying information yields a smaller payoff.

\section{EXPERIMENTAL DESIGN}

The experiment was conducted at the Universitat Pompeu Fabra in Barcelona. Participants were undergraduate students with majors in economics, business, or the humanities. There were a total of 78 subjects in 6 separate sessions. Average earnings were approximately $\$ 10$ and the sessions averaged about 75 minutes. Participants were seated in carrels separated by dividers, so that information and choices were private.

The precise instructions used are shown in Appendix 1. Sellers were clustered on one side of the room, with buyers on the other. It was common knowledge that each buyer was paired with one seller for the duration of the experiment. This duration was stochastic - after 
period 10, an eight-sided die was tossed. ${ }^{10}$ If the outcome was 1 or 2 , the experiment ended immediately. Otherwise, we proceeded to the next round, after which the die was tossed again. Thus, after period 10 there was always a $75 \%$ chance that there would be another period and the expected number of future periods is always 4. The results indicate that this approach was successful in preventing unraveling, even in late periods. ${ }^{11}$ The longest session lasted 18 periods.

Prior to each period, each buyer chose whether to purchase information and indicated this choice on a decision form. A coin was flipped in the sellers' area, so that the sellers could see the true asset value for that period, but the buyers could not. At this point, the information purchase decisions were distributed to the sellers. If the buyer wished to purchase information, the seller indicated a value on a separate sheet. It was common knowledge that sellers were not constrained to report accurately. If no information was purchased, this sheet was left blank. These asset value reports were passed out to the corresponding buyers, who then indicated on another sheet whether to purchase the asset in that period. Finally, the asset purchase decision slips were given to the information sellers and the asset value was revealed to everyone. All of these decision forms are shown in Appendix 2.

Buyers were endowed with 630 pesetas, in addition to the 500 peseta show-up fee received by all. Each information purchase cost 50 pesetas, this amount being transferred from the buyer's account to the seller's account. The asset cost 160 pesetas and had a value of either 0 or 320 pesetas, depending on the result of the coin toss. If a buyer purchased information and also purchased the asset, the seller received a bonus of 40 pesetas (for 90 pesetas total). This bonus was $25 \%$ of the cost of the asset. If no information was bought, the

\footnotetext{
${ }^{10}$ Marimon and Sunder (1993) adapt an infinite OLG model to a finite experiment, using a forecast technique. They credit Lim, Prescott, and Sunder (1993) for their design. To our knowledge, the first use of a stochastic termination was in Cason (1995)

${ }^{11}$ It should be clear that there are some limitations to this technique. It is necessary to estimate the ending time for a session when recruiting subjects. Even if this were not so, subjects form expectations about the time a session will end. If the session gets "too close" to this time, participants may not believe that the experimenter will continue the session indefinitely. To help minimize this problem, sessions were advertised as two hours in length, well in excess of the actual time needed.
} 
seller received 0 . These parameter values were common knowledge and were chosen to give roughly equal payoffs to buyers and sellers if information was always purchased and reporting was always truthful. 


\section{RESULTS}

The results indicate that reputation is generally a stronger force than the temptation to manipulate buyers for immediate reward. Fully detailed results for the 6 sessions can be found in Appendix 3. A summary is presented in Table 1:

\begin{tabular}{cccc}
\multicolumn{4}{c}{ Table 1 - Information sellers' behavior } \\
Asset Value & Periods & Sales & Truth \\
High & 41 & 166 & $161(97 \%)$ \\
Low & 41 & 164 & $133(81 \%)$ \\
Total & 82 & 330 & $294(89 \%)$
\end{tabular}

When the asset value was low (high), information sellers reported the value with an $81 \%$ (97\%) probability. Overall, the truth was stated $89 \%$ of the time. Ex post, a buyer could expect to earn money by buying information and treating it as accurate, since [1/2*(.97*160) $1 / 2 *(.19 * 160)]-50=12.4$. An uninformed player who guessed high (or low) asset value every time would have earned 0 .

Appendix 4 shows that the percentage of truth-telling when the asset value is low does not change much over time. This supports the conclusion that little unraveling occurs, as the proportion of honesty when the asset value is low is still $77 \%$ for periods $11-18 .{ }^{12}$ A case by case analysis of the behavior for the 37 (of 39 potential) sellers who actually sell information finds that 14 always told the truth, 13 lied once, and 10 lied more than once. Six buyers never again bought information after being told a lie and 5 others stopped buying after two false reports. This is consistent with the view that nearly half of the subjects (11 of 23) played either a grim trigger or near-grim trigger strategy (allow one lie), while others employed

\footnotetext{
${ }^{12}$ However, it should be noted that there are other factors involved here, so that this is not conclusive. Specifically, buyers' eventually stop buying information from manipulative sellers, so that the less honest sellers make fewer sales over time.
} 
temporary punishment phases. There was no punishment for only 6 of the 33 lies not occurring in the last period. Generally, temporary punishment phases lasted for 2-4 periods.

Another measure of the effectiveness of this information market is the observed likelihood that a buyer's decision to buy (or not buy) the asset is optimal. We find that 403 of 543 asset decisions, or $74 \%$, were correct. While this is a substantial improvement over the $50 \%$ expectation absent information purchase, it is far from perfect. The asset market "efficiency" would be higher if information were purchased more frequently. While the percentage of truth-telling was high enough to support consistent information buying, in fact the overall purchase rate of information was only $61 \%$. Nonetheless, nonparametric tests show that our market for information significantly improves the accuracy of asset purchase decisions. Using all asset decisions, we have $\chi^{2}=67.66, \mathrm{p} \ll .01$. A binomial test on individual participants' success rates also rejects the null hypothesis of equality at $\mathrm{p}<<.01$ ( $\mathrm{Z}$ $=4.81$ ), as more than $50 \%$ of the asset purchase decisions were correct for 34 of 39 buyers. ${ }^{13}$

\subsection{Discussion}

In the model presented, both the trigger-strategy equilibrium and the mixed-strategy equilibrium are subgame-perfect. In the case of the mixed-strategy equilibrium, we must also address the question of whether a suggested steady-state equilibrium can be started-up. Why should the receiver buy information at time 1 given that there is no previous history and that there is some probability that the seller will lie? If a credible randomizing mechanism can be observed, this presents no problem. However, if a probability estimate can only be made based on historical behavior, the likelihood of an honest report is unclear at time 1. Under the assumption that a receiver wishes to maximize the total expected profits over the span of the repeated game, the receiver should explore the informational resources available, even if his $a$ priori estimate of $\mathrm{j}$ is quite high. ${ }^{14}$

\footnotetext{
${ }^{13}$ Two buyers made correct asset purchase decisions exactly $50 \%$ of the time.

${ }^{14}$ The data show that 37 of 39 potential information buyers did purchase information on at least one occasion.
} 
A related point concerns the use of some form of trigger strategy. Since there is no previous communication or history between players, there is no obvious ex ante reason for a sender to believe that a receiver is following a trigger strategy. However, there may be some perceived social norms that: 1) people assume that others are honest until they are given evidence to the contrary; and 2) people react adversely when they learn that they have been deceived. These two conditions describe a trigger strategy and the degree of the adverse reaction to deception influences the length of the punishment phase. If a sender believes that the receiver is playing a trigger strategy with a sufficiently long punishment phase, he should never lie. ${ }^{15}$ On the other hand, if the sender believes that the receiver buys information if and only if it has positive expected value, the mixed-strategy equilibrium with the maximal $\mathrm{j}$ is optimal for the sender. If the sender is uncertain of the receiver's type of strategy, he would select a value of $\mathrm{j}$ between 0 and the maximum permitted by the Folk Theorem.

In fact, we find that the observed value for $\mathrm{j}$ is .19 , near the midpoint of the possible range of $[0, .375]$ for which there should be a market for information. This may reflect the sender's uncertainty regarding the receiver's response to deception. In fact, it appears that receivers do generally punish deception, at least temporarily. It seems likely that less uncertainty concerning players' strategies and rationality would lead to more consistency in behavior and greater efficiency.

The relatively low rate of information purchase may seem a bit surprising at first, but is easier to understand with a bit of reflection. For an information seller to be honest, he must either have a taste for truth-telling or believe that, while a buyer will continue to buy information if he expects it to be accurate, he will stop buying (at least temporarily) if he discovers he has been deceived. However, consider the thought process of a prospective buyer. First, he knows that information reports may be inaccurate and he may have an

\footnotetext{
${ }^{15}$ This case includes the possibility of an "irrational" response to deception (non-maximization of material payoffs), perhaps driven by the psychological disutility of being a victim of such deception.
} 
aversion to being at the mercy of an anonymous person. Second, he must believe that the seller is not only rational, but also believes that the buyer is rational.

The necessity for higher order beliefs makes the purchase of information less likely, given the abundant experimental evidence of subjects' finite depth of reasoning. ${ }^{16}$ In addition, as the willingness to purchase information decreases as $|\mathrm{k}-1 / 2|$ increases, the observed underpurchase can be justified on the grounds of optimism and pessimism alike.

Finally, we would expect unraveling if senders become "nervous" as either the time T increases or as low outcomes seem to be too prevalent. However, we do not observe any dramatic unraveling, although there is some evidence that sellers get nervous. This suggests that the sender's subjective expectations for the remaining duration of the session and the likelihood of future outcomes do not fall below the joint threshold values. If it was anticipated that this would not be the case at any point in the session, the market should unravel all the way back to the first period. It appears that this element of the design was successful.

\section{APPLICATIONS}

Our model and our results lend themselves to a number of applications. We briefly present some of these and develop the application to financial markets and business law. Each application is contingent on the less-informed being able to verify ex post the accuracy of the information or news that they receive. The model and the experiment are based on a one-toone relationship and, in that sense, our considerations refer to a small market for information (small in the number of agents). In the applications below, it is possible to argue that the number of buyers and sellers is usually small, each buyer and seller having a significant market power. Information in these markets is not usually provided competitively, as it is difficult for one to shop for privileged information.

\subsection{Stability of cartels}

\footnotetext{
${ }^{16}$ One example of this can be seen in the Nagel (1995) guessing game.
} 
Asymmetry of information should not affect the stability of a cartel. The members with more information have a reduced incentive to manipulate information as long as they are paid by other members of the cartel. Side payments from those with less information to those with more information contributes to the stability of the cartel. 


\subsection{Media behavior}

As long as the gains from setting a given political agenda or defaming public figures are not large relative to the revenues from selling newspapers, the market is self-regulating. Defamation and partisan oriented news occur, but are limited by economic considerations. The result is also applicable to financial journalists or brokers who may be offered bribes by companies to tout their offerings to the public.

\subsection{Political economy}

Given at least a medium-run horizon, voters' ability to eventually learn the truth gives politicians incentives to reduce their likelihood of manipulating public information, in order to cover their vested interests. In addition, any long-run concerns about how history will record their performance (perhaps not an insignificant factor) contribute to a self-regulated political market. This is not to imply that there is no manipulation of information, but rather that regulating the political market may be inefficient.

\subsection{Financial markets and business law}

We find that, in a repeat-game situation with no fixed end, if the gains from manipulating information are not extremely large relative to the revenues from selling information, the market can actually be self-regulated. Self-regulation does not eliminate manipulation altogether but reduces its likelihood. In comparison, regulation by a third party may be inefficient because the gains in avoiding manipulation are not large, and monitoring and enforcement costs are incurred.

There are implications for the regulation of insider information exchange and criminal liability. One criminal offense is that the sender gets a kickback. Here our result suggests that unless the punishment is very tough, we should expect little impact from regulation. Other offenses include selling inside information and manipulating information; while punishment may reduce incentives to exchange this information, the market itself may 
provide disincentives for manipulation. Thus, criminal regulation may have limited marginal effectiveness on distortions in the market for insider information.

In the context of mandatory disclosure, we can think of our model as Coffee's story (1984), as we address the interval between the disclosure and the market absorption of information (the asset value becomes common knowledge at the end of each period). Coffee suggests that the time interval is sufficient to assure profitable trade and satisfy the mandate of the laws. Our results support this view.

The main legal theory on regulating inside information seems to be the misappropriation theory that rejects what has been called "the Wall Street honor code" by which individuals trade inside information in the shadow of the law. As Painter, Krawiec and Williams (1998) have pointed out, the regulatory agency finds the honor code difficult to break. The results suggest an explanation for this observation: the honor code is induced by reputation gains and there is virtually no transaction cost, since the code is not negotiated. The code emerges "spontaneously" as insiders learn that manipulating information induces a loss of future gains, and so buyers find it useful to buy information.

The legal policy of conditioning criminal liability on the existence of a fiduciary relationship seems appropriate in the context of our results. ${ }^{17}$ Specifically, the more intense is a relationship (in sense of duration), the less problematic is information manipulation and the more likely inside information will be purchased and used. An interesting point is to question liability in terms of who solicits information and who provides it. It seems that the legal practice is to be more lenient with those providing the information than with those asking for information. ${ }^{18}$

In terms of our game, we could rationalize the legal practice by observing that the buyer makes the first decision (whether to buy information). But taking into account how the game operates, it would seem more sensible to be stricter with the seller. By being

\footnotetext{
${ }^{17}$ See DeMarzo, Fishman, and Hagerty (1998)

${ }^{18}$ See United States v. O'Hagan, where an attorney used confidential client information to trade in the stock market.
} 
lenient with the buyer and strict with the seller, the regulator is providing an extra incentive for the seller to manipulate information: it is more likely that both are playing a one-shot game (given that if detected and punished, the seller is basically out of the market). The consequence is that buying information is less attractive, as intended by the regulator.

Note that it is easier to legally constrain the seller from being in the market than the buyer, as the seller is someone in a privileged position and so is much easier to detect and punish. As in Brudrey (1979), our model suggests that inside trading is inequitable because it gives insiders a monopoly on the use of corporate information. However, following the criticism of Carlton and Fischel (1983) and Haddock and Macey (1987, 1988), this paper points out that reputation reduces inequity in the sense that the monopoly power is reduced by the incentive to reveal accurate information.

In conclusion, if the main concern of the analysis is manipulation of information, the results presented are optimistic because individuals seem to be fairly honest even in presence of commissions. In contrast, if the main concern is the existence of a market for insider information, the results presented are quite negative because demand and supply exists even when some dishonesty is likely.

\section{CONCLUSION}

The results indicate that it may not be necessary to regulate environments where there is an information asymmetry. Even in a finite game, sellers' behavior appears to be constrained by reputation and foregone future earnings. Beliefs about rationality are sufficient to sustain more Pareto-efficient outcomes than are possible in a one-shot game. As we have limited the opportunity for insider gains in the asset market, we find that manipulation is not a major issue in our repeated-game setting.

Our model captures the essence of the observed behavior. There is a substantial degree of information under-purchase, probably due to the more stringent rationality beliefs required on the part of the buyers. Sellers appear to be following either mixed strategies or expect 
buyers to follow grim trigger or near-grim trigger strategies (27/37 sellers lied one or less times). The limited number of periods makes it impossible to distinguish between these two explanations; however, it seems likely that there are sellers in each of these categories. The observed likelihood for honestly reporting a low asset value (.81) is higher than the Folk Theorem's threshold value (.625), perhaps reflecting sellers' uncertainty about whether buyers are following some form of trigger strategy or simply purchase information when the perceived expected value is positive.

In many real contexts, our results have immediate applicability. While government intervention and regulation may be advisable in many instances, the potential for selfregulation of information markets is definitely present. Sometimes agents realize that it is worthwhile to maintain a reputation for honesty. 


\section{REFERENCES:}

Admati, A. and P. Pfleiderer, 1986, "A Monopolistic Market for Information," Journal of Economic Theory, 39, 400-38.

Benabou, R. and G. Laroque, 1992, "Using Privileged Information to Manipulate Markets: Insiders, Gurus, and Credibility,” Quarterly Journal of Economics, 107, 921-58.

Benoit, J.-P. and V. Krishna, 1985, "Finitely Repeated Games," Econometrica, 53, 905-922

Benoit, J.-P. and V. Krishna, 1987, "Nash Equilibria of Finitely Repeated Games," International Journal of Game Theory, 16, 197-204

van Bommel, J., 1998, “Rumors," mimeo

Brudrey, V., 1979, "Insiders, Outsiders and Informational Advantages under the Federal Securities Law," Harvard Law Review, 93, 322-376.

Carlton, D., and Fischel, D., 1983, "The Regulation of Insider Trading," Stanford Law Review, 35, 857-895.

Cason, T., 1995, "Cheap Talk Price Signaling in Laboratory Markets," Information Economics and Policy, 7, 183-204

Coffee, J., 1984, "Market Failure and the Economic Case for a Mandatory Disclosure System," Virginia Law Review, 70, 717-753.

Copeland, T. and D. Friedman, 1987, "The Effect of Sequential Information Arrival on Asset Prices: An Experimental Study,” Journal of Finance, 42, 763-98

Copeland, T. and D. Friedman, 1991, "Partial Revelation of Information in Experimental Asset Markets," Journal of Finance, 46, 265-81

Copeland, T. and D. Friedman, 1992, "The Market Value of Information: Some Experimental Results," Journal of Business, 65, 241-66

Crawford, V. and J. Sobel, 1982, "Strategic Information Transmission," Econometrica, 50, $1413-1451$.

van Damme, E., Stability and Perfection of Nash Equilibria, 1991, 2nd edition, SpringerVerlang: Berlin

Demarzo, P., M. Fishman and K. Hagerty, "The Optimal Enforcement of Insider Trade Regulations," Journal of Political Economy, 106, 602-32 
Forsythe, R., T. Palfrey and C. Plott, 1984, "Futures Markets and Laboratory Efficiency: A Laboratory Examination," Journal of Finance, 39, 955-81

Friedman, D., 1993, "Privileged Traders and Market Efficiency: A Laboratory Study,” Journal of Financial and Quantitative Analysis, 28, 515-34

Haddock, D. and Macey, J., 1986, "A Coasian Model of Insider Trading," Northwestern University Law Review, 80, 1449-1472.

Haddock, D. and Macey, J., 1987, "Regulation on Demand: a Private Interest Model, with an Application to Insider Trading Regulation," Journal of Law and Economics, 30, 311-352.

Kreps, D. and R. Wilson, 1982, "Reputation and Imperfect Information," Journal of Economic Theory, 27, 253-279.

Lim, S., E. Prescott and S. Sunder, 1994, "Stationary Solution to the Overlapping Generations Model of Fiat Money: Experimental Evidence," Empirical Economics, 19, 255-77

Marimon, R. and S. Sunder, 1993, "Rational Expectations vs. Adaptive Behavior in a Hyperinflationary World: Experimental Evidence,” Econometrica, 61, 1073-1108

Nagel, R., 1995, "Unraveling in Guessing Games: An Experimental Study," American Economic Review, 85, 1313-26

Painter, R., Krawiec, K., and C. Williams, 1998, "Don't Ask, Just Tell: Insider Trading after United States v. O'Hagan,” Virginia Law Review, 84, 153-228.

Plott, C. and S. Sunder, 1982, "Efficiency of Experimental Security Markets with Insider Information: An Application of Rational-Expectations Models," Journal of Political Economy, 90, 663-98

Plott, C. and S. Sunder, 1988, "Rational Expectations and the Aggregation of Diverse Information in Laboratory Security Markets," Econometrica, 56, 1085-1118

Reichman, N., 1993, "Insider Trading," in Beyond the Law: Crime in Complex Organizations, Crime and Justice, A Review of the Research, 18, 55-96

Sobel, J., 1985, “A Theory of Credibility,” Review of Economic Studies, 52, 557-573.

Sunder, S., 1992, “Market for Information: Experimental Evidence,” Econometrica, 60, 66795

Sunder, S., 1995, "Experimental Asset Markets: A Survey," in J. Kagel and A. Roth, The Handbook of Experimental Economics, 445-500 


\section{APPENDIX 1 - INSTRUCTIONS}

Thank you for participating in this experiment. Each participant will receive 500 pesetas as a show-up fee, in addition to his or her accumulated account balance at the end of the experiment. Each person will be paid individually and privately.

People will be matched in anonymous pairs, so that no one will know with whom s/he is paired. People will be randomly divided into two groups: Information buyers (B) and information sellers (S). There will be a number of periods in this experiment. Each $B$ will be paired with the same $S$ in every period of the experiment.

\section{Earnings:}

In every period, each B will have a choice of whether to purchase an asset which has two possible payoffs in that period and only in that period. The cost of this asset is 160 pesetas. In each period, a coin will be flipped to determine the value of the asset. If the coin result is "heads", the asset has a value of 320 pesetas. If the coin result is "tails", the asset has a value of 0 pesetas. In the next period, each B will again choose whether to buy a new asset. Once again, the price of the asset will be 160 pesetas and its value will be determined by the result of the coin flip in that round.

When the coin is flipped, the results of the coin flip will be shown to all information sellers (S) and only to the information sellers. Thus, each $\mathrm{S}$ knows the value of the asset. In each round, before each B makes a decision about whether to purchase the asset, s/he will have the opportunity to purchase information about the asset's value from the $S$ with whom $\mathrm{s} / \mathrm{he}$ is paired. A form is provided for this purpose for each round; the choice to purchase or not purchase information will be communicated to the $S$ for each $B$. In each round, the cost of this information is 50 pesetas, which would be transferred from B's account to S's account if information is purchased by B. Each B will be endowed with 630 pesetas (separate from the show-up fee) with which s/he may purchase assets and/or information.

In each period, if B chooses to purchase information, $\mathrm{S}$ may tell the truth about the asset value or may give false information to B. A form is provided for this purpose for each round and will be delivered to each $\mathrm{B}$ who chooses to purchase information. If you purchase information in a round, please take care that other B's do not see this information. If $B$ does purchase information and B then decides to buy the asset, $\mathrm{S}$ receives a bonus of 40 pesetas ( $25 \%$ of the asset cost), in addition to the 50 pesetas for the sale of the information; otherwise, $\mathrm{S}$ receives only the proceeds, if any, from the sale of information. After each $\mathrm{B}$ has made the asset purchase decision for that period, the asset value will be revealed and we continue as described above. The coin flip will be repeated and observed by the S's; B's will once again choose whether to purchase information about the asset value and whether or not to purchase the asset. An account record sheet will be provided to each person, to facilitate personal record-keeping, if desired.

The number of periods $(\mathrm{N})$ is uncertain and will be determined in the following manner: There will be at least 10 periods. After period 10, we will roll an eight-sided die. If the die comes up 
$3,4,5,6,7$ or 8 , we will continue for another period. At the end of that period, we will again roll the die. Once again, there will be another period if the die comes up 3, 4, 5, 6, 7 or 8 . This process will continue until the die is rolled after a round and comes up 1 or 2 , at which point the experiment will be over. At any time after period 10, the expected number of further periods is 4 . (A mathematical proof of this will be provided upon request.) 


\section{APPENDIX 2 - DECISION FORMS}

1) Information purchase:

Period

Number

Buy Information?

YES NO

2) Information value:

\section{Period \\ Number}

\section{Asset value}

0

320

3) Asset purchase:

Period

Number

Buy Information?

YES NO




\section{APPENDIX 3 - RESULTS}

Session 1

$\begin{array}{lllllllll} & 1 & 2 & 3 & 4 & 5 & 6 & 7 & \text { Truthful reporting } \\ 1+ & \text { b+b } & \text { b+b } & \text { n b } & \text { b+b } & \text { b+b } & \text { b+b } & \text { b+b } & 6 / 6 \\ 2- & \text { n n } & \text { b-n } & \text { n n } & \text { b-n } & \text { b-n } & \text { b-n } & \text { b-n } & 5 / 5 \\ 3+ & \text { b+b } & \text { b+b } & \text { n b } & \text { n b } & \text { n n } & \text { n b } & \text { b+b } & 3 / 3 \\ 4- & \text { n b } & \text { b-n } & \text { n b } & \text { b+b } & \text { b-n } & \text { n b } & \text { b-n } & 3 / 4 \\ 5- & \text { b-n } & \text { b-n } & \text { b-n } & \text { b-n } & \text { b+b } & \text { b-n } & \text { b-n } & 6 / 7 \\ 6+ & \text { b+b } & \text { b+b } & \text { n b } & \text { b+b } & \text { n n } & \text { b+b } & \text { b+b } & 5 / 5 \\ 7+ & \text { b+b } & \text { b+b } & \text { n b } & \text { b+b } & \text { n b } & \text { b+b } & \text { b+b } & 5 / 5 \\ 8- & \text { b+b } & \text { b-n } & \text { n b } & \text { b+b } & \text { n b } & \text { b-n } & \text { b-n } & 3 / 5 \\ 9+ & \text { n b } & \text { b+b } & \text { b+b } & \text { n n } & \text { n b } & \text { b+b } & \text { b+b } & 4 / 4 \\ 10- & \text { b-n } & \text { b+b } & \text { b+b } & \text { n n } & \text { n n } & \text { b-n } & \text { b-n } & 3 / 5 \\ 11+ & \text { b+b } & \text { n b } & \text { n b } & \text { n b } & \text { n n } & \text { b+b } & \text { b+b } & 3 / 3 \\ 12+ & \text { b+b } & \text { n n } & \text { n n } & \text { b+b } & \text { n b } & \text { b+b } & \text { b+b } & 4 / 4 \\ 13- & \text { b-n } & \text { n n } & \text { b-n } & \text { n n } & \text { n n } & \text { b+n } & \text { b-n } & 3 / 4\end{array}$

Key to reading this chart: The first column is the period, with the + or - after it indicating a high or low true asset value. The data for each pair in each period is in a triplet. The 1st element, $b$ or $n$, indicates whether the buyer bought information in that period. The middle element is either + or - indicates the announcement made by the information seller; if no information was purchased, this is a blank space. The third element, $b$ or $n$, indicates whether the buyer purchased the asset in that period.

\begin{tabular}{llllllll} 
& & & & \multicolumn{5}{c}{ Session 2} \\
& 1 & 2 & 3 & 4 & 5 & 6 & Truthful reporting \\
$1-$ & b+b & b-n & b-n & n n & b-n & b+b & $3 / 5$ \\
$2-$ & b-n & b-n & b-n & b+b & b-n & b-n & $5 / 6$ \\
$3+$ & b+b & n b & b+b & n b & n b & b+b & $3 / 3$ \\
$4+$ & b+b & b-n & b+b & b+b & n b & b+b & $4 / 5$ \\
$5-$ & b+b & n n & b-n & n n & b-n & b-n & $3 / 4$ \\
$6-$ & n b & b+b & b-n & n n & n b & b-n & $2 / 3$ \\
$7+$ & b+b & n n & b+b & n b & b+b & n n & $3 / 3$ \\
$8-$ & b+b & n n & b+b & n b & b-n & b+b & $1 / 4$ \\
$9-$ & n b & n b & b-n & n b & b-n & b-n & $3 / 3$ \\
$10+$ & n b & n n & b+b & b+b & n n & n b & $2 / 2$ \\
$11-$ & n b & n b & b+b & n b & b-n & n b & $1 / 2$ \\
$12-$ & b-n & n n & n b & n n & b-n & n b & $2 / 2$
\end{tabular}


Session 3

$\begin{array}{llllllll} & 1 & 2 & 3 & 4 & 5 & 6 & \text { Truthful reporting } \\ 1+ & \text { n b } & \text { b+b } & \text { n b } & \text { n b } & \text { b+b } & \text { b+b } & 3 / 3 \\ 2- & \text { n n } & \text { b-n } & \text { n b } & \text { b-n } & \text { b-n } & \text { b-n } & 4 / 4 \\ 3+ & \text { b+b } & \text { b+b } & \text { b+b } & \text { b+b } & \text { b+b } & \text { b+b } & 6 / 6 \\ 4- & \text { b+n } & \text { b+b } & \text { b+b } & \text { b-n } & \text { b-n } & \text { b-n } & 3 / 6 \\ 5- & \text { n b } & \text { n b } & \text { n b } & \text { b-n } & \text { b-n } & \text { b-n } & 3 / 3 \\ 6- & \text { n b } & \text { b-n } & \text { b+b } & \text { n b } & \text { n b } & \text { b-n } & 2 / 3 \\ 7+ & \text { n b } & \text { b+b } & \text { n b } & \text { b-n } & \text { b-n } & \text { b+b } & 2 / 4 \\ 8+ & \text { n b } & \text { b+b } & \text { n b } & \text { n b } & \text { b+b } & \text { b+b } & 3 / 3 \\ 9- & \text { n n } & \text { b-n } & \text { n n } & \text { b+b } & \text { b-b } & \text { b-n } & 3 / 4 \\ 10- & \text { b-n } & \text { b-n } & \text { b+b } & \text { n n } & \text { b-n } & \text { b-n } & 4 / 5 \\ 11- & \text { n n } & \text { b-n } & \text { n b } & \text { n b } & \text { n n } & \text { b-n } & 2 / 2 \\ 12- & \text { b+b } & \text { b-n } & \text { n b } & \text { n b } & \text { n n } & \text { b-n } & 2 / 3\end{array}$

Session 4

\begin{tabular}{|c|c|c|c|c|c|c|c|c|c|}
\hline & 1 & 2 & 3 & 4 & 5 & 6 & 7 & 8 & Truthful reporting \\
\hline $1-$ & b-n & b-n & b-n & b-n & b-n & $b-b$ & b-n & b-n & $8 / 8$ \\
\hline $2-$ & b-n & b-n & b-n & b-n & b-n & b-n & $\mathrm{n} \mathrm{n}$ & b-n & $7 / 7$ \\
\hline $3+$ & $b+b$ & $b+b$ & $b+b$ & $b+b$ & $b+b$ & $b+b$ & $b+b$ & $b+b$ & $8 / 8$ \\
\hline $4+$ & $b+b$ & $b+b$ & $b+b$ & $b+b$ & $b+b$ & $b+b$ & $b+b$ & $b+b$ & $8 / 8$ \\
\hline $5+$ & $b+b$ & $b+b$ & $b+b$ & $b+b$ & $b+b$ & $b+b$ & $b+b$ & $b+b$ & $8 / 8$ \\
\hline 6- & b-n & b-n & b-n & b-n & b-n & $b+b$ & $\mathrm{n} \mathrm{n}$ & b-n & $6 / 7$ \\
\hline 7- & b-n & b-n & b-n & b-n & b-n & b-n & $\mathrm{n} \mathrm{n}$ & b-n & $7 / 7$ \\
\hline 8- & b-n & b-n & b-n & b-n & $b+b$ & $b+b$ & b-n & $\mathrm{n} \mathrm{n}$ & $5 / 7$ \\
\hline $9+$ & $b+b$ & $b+b$ & $b+b$ & $b+b$ & $\mathrm{nb}$ & $\mathrm{n} \mathrm{b}$ & $\mathrm{n} \mathrm{b}$ & $b+b$ & $5 / 5$ \\
\hline 10- & b-n & b-n & b-n & b-n & $\mathrm{n} \mathrm{n}$ & $\mathrm{nb}$ & $\mathrm{n} \mathrm{n}$ & b-n & $5 / 5$ \\
\hline $11+$ & $b+b$ & $b+b$ & $b+b$ & $b+b$ & $\mathrm{nb}$ & $b+b$ & $b+b$ & $b+b$ & $7 / 7$ \\
\hline $12+$ & $b+b$ & $b+b$ & $b+b$ & $b+b$ & $\mathrm{n} \mathrm{n}$ & $b+b$ & $\mathrm{n} \mathrm{b}$ & $b+b$ & $6 / 6$ \\
\hline $13+$ & $b+b$ & $b+b$ & $b+b$ & $b+b$ & $b+b$ & $b+b$ & $b+b$ & $b+b$ & $8 / 8$ \\
\hline $14+$ & 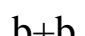 & & & $+\mathrm{th}$ & $+\mathrm{h}$ & $+h$ & $\mathrm{~h}$ & $h+b$ & $7 / 7$ \\
\hline
\end{tabular}


Session 5

\begin{tabular}{|c|c|c|c|}
\hline & 1 & 2 & 3 \\
\hline $1+$ & $b+b$ & $b+b$ & $\mathrm{n} \mathrm{b}$ \\
\hline $2-$ & b-n & $b+b$ & $\mathrm{nb}$ \\
\hline 3- & $\mathrm{nb}$ & $\mathrm{n} \mathrm{b}$ & $\mathrm{nb}$ \\
\hline $4+$ & $\mathrm{n} \mathrm{n}$ & $\mathrm{n} \mathrm{b}$ & $\mathrm{n} \mathrm{b}$ \\
\hline $5+$ & $\mathrm{n} \mathrm{n}$ & $\mathrm{n} \mathrm{b}$ & $\mathrm{nb}$ \\
\hline $6+$ & $b+b$ & $\mathrm{n} \mathrm{b}$ & $\mathrm{nn}$ \\
\hline $7+$ & $\mathrm{n} \mathrm{b}$ & $\mathrm{n} n$ & $\mathrm{n} \mathrm{n}$ \\
\hline $8+$ & $\mathrm{n} \mathrm{b}$ & $\mathrm{n} \mathrm{n}$ & $\mathrm{nb}$ \\
\hline 9- & $\mathrm{n} \mathrm{n}$ & $\mathrm{n} \mathrm{b}$ & $\mathrm{n} \mathrm{n}$ \\
\hline $10-$ & $\mathrm{n} \mathrm{b}$ & $\mathrm{n} \mathrm{b}$ & $\mathrm{n} n$ \\
\hline 11- & $\mathrm{n} \mathrm{b}$ & $\mathrm{n} \mathrm{b}$ & $\mathrm{n} \mathrm{n}$ \\
\hline 12- & $\mathrm{nb}$ & $\mathrm{n} \mathrm{b}$ & $\mathrm{n} \mathrm{n}$ \\
\hline $13+$ & $\mathrm{n} \mathrm{n}$ & $\mathrm{n} \mathrm{b}$ & $\mathrm{nb}$ \\
\hline
\end{tabular}

Truthful reporting

$2 / 2$

$1 / 2$

$0 / 0$

$1 / 1$

$0 / 0$

$1 / 1$

$0 / 0$

$0 / 0$

$0 / 0$

$0 / 0$

$0 / 0$

$0 / 0$

$0 / 0$

Session 6

$\begin{array}{llllllllll} & 1 & 2 & 3 & 4 & 5 & 6 & 7 & 8 & \text { Truthful reporting } \\ 1+ & \text { b+b } & \text { b+b } & \text { n b } & \text { n b } & \text { b+b } & \text { n b } & \text { n b } & \text { n b } & 3 / 3 \\ 2+ & \text { b+b } & \text { b+b } & \text { n n } & \text { b+b } & \text { b+b } & \text { n b } & \text { b+b } & \text { b+b } & 6 / 6 \\ 3+ & \text { b+b } & \text { b+n } & \text { b+b } & \text { n b } & \text { b+b } & \text { n n } & \text { b+n } & \text { n n } & 5 / 5 \\ 4+ & \text { b+b } & \text { b+n } & \text { b+b } & \text { n b } & \text { b+b } & \text { n n } & \text { b+b } & \text { b+b } & 6 / 6 \\ 5- & \text { b-n } & \text { n n } & \text { b-n } & \text { n b } & \text { b-b } & \text { n n } & \text { b-n } & \text { n n } & 4 / 4 \\ 6+ & \text { b+b } & \text { n b } & \text { b-n } & \text { n b } & \text { b+b } & \text { n b } & \text { b+b } & \text { b+b } & 4 / 5 \\ 7+ & \text { b+b } & \text { b+b } & \text { n b } & \text { b+b } & \text { b+b } & \text { n-n } & \text { b+b } & \text { n b } & 5 / 5 \\ 8+ & \text { b+n } & \text { b+n } & \text { b-n } & \text { n-n } & \text { b+b } & \text { n b } & \text { b+n } & \text { b+n } & 5 / 6 \\ 9- & \text { b-n } & \text { b-n } & \text { n b } & \text { n b } & \text { b-n } & \text { n n } & \text { b-n } & \text { b-n } & 5 / 5 \\ 10- & \text { b-n } & \text { b-n } & \text { n b } & \text { n b } & \text { b-n } & \text { n n } & \text { b-n } & \text { b-n } & 5 / 5 \\ 11- & \text { b-n } & \text { b-n } & \text { b-n } & \text { n b } & \text { b+b } & \text { n n } & \text { b-n } & \text { b-n } & 5 / 6 \\ 12+ & \text { b+b } & \text { b+b } & \text { n b } & \text { n b } & \text { n n } & \text { n b } & \text { b+b } & \text { n b } & 3 / 3 \\ 13- & \text { b-n } & \text { b-n } & \text { n b } & \text { n b } & \text { n n } & \text { n n } & \text { b-n } & \text { b-n } & 4 / 4 \\ 14+ & \text { b+b } & \text { b+b } & \text { b+b } & \text { n b } & \text { n n } & \text { n n } & \text { b+b } & \text { b+b } & 5 / 5 \\ 15+ & \text { b+n } & \text { b+n } & \text { b+n } & \text { n b } & \text { n b } & \text { n n } & \text { b+n } & \text { b+n } & 5 / 5 \\ 16- & \text { b-n } & \text { b-n } & \text { b+b }+ \text { n n } & \text { n b } & \text { n n } & \text { b+b } & \text { b-n } & 3 / 5 \\ 17+ & \text { b+b } & \text { b+b } & \text { n b } & \text { n b } & \text { n b } & \text { n n } & \text { n b } & \text { n n } & 2 / 2 \\ 18- & \text { b-n } & \text { b-n } & \text { n b } & \text { n n } & \text { n b } & \text { n n } & \text { n b } & \text { b+b } & 2 / 3\end{array}$




\section{APPENDIX 4}

\section{TRUTHFUL REPORTING WHEN THE ASSET VALUE IS LOW}

$\begin{array}{cccc}\text { Period } & \text { Information Purchases } & \text { Truthful Reporting } & \% \text { Truthful } \\ 1 & 13(14) & 11 & 85 \\ 2 & 24(26) & 22 & 92 \\ 3 & 0(4) & 0 & - \\ 4 & 10(17) & 6 & 60 \\ 5 & 18(27) & 16 & 89 \\ 6 & 13(20) & 10 & 77 \\ 7 & 7(8) & 7 & 100 \\ 8 & 16(21) & 9 & 56 \\ 9 & 12(24) & 11 & 92 \\ 10 & 20(33) & 17 & 85 \\ 11 & 10(24) & 8 & 80 \\ 12 & 5(16) & 4 & 80 \\ 13 & 8(15) & 7 & 88 \\ 14 & 0(0) & 0 & - \\ 15 & 0(0) & 0 & - \\ 16 & 5(8) & 4 & 60 \\ 17 & 0(0) & 0 & - \\ 18 & 3(8) & 2 & 67\end{array}$

The numbers in parentheses indicate the aggregations of the number of buyers who could have purchased information. 


\section{FIGURE 1}

$\mathrm{V}=-1$ is the low asset value; $\mathrm{V}=1$ is the high asset value. $\mathrm{S}=-1$ is the signal that the asset value is low; $\mathrm{S}=1$ is the signal that the asset value is high. $\mathrm{p}$ is the price of information, $\mathrm{q}$ is the bonus for the seller, and $r / 2$ is the price of the asset, with a high value of $r$ and a low value of $0 . B_{i}$ means buy information, $N_{i}$ means don't buy information; $B_{a}$ means buy the asset, $N_{a}$ means don't buy the asset. $\mathrm{b}$ is the buyer and $\mathrm{s}$ is the seller. The dotted lines indicate that the buyer does not know the true asset value when deciding to buy either information or the asset. 